\title{
Redefining Thirst: Beyond Dehydration and toward a Holistic Biopsychological Model
}

\author{
Harriet A. Carroll \\ Clinical Research Centre, Cardiovascular Research - Hypertension, Lund University, Lund, Sweden
}

\section{Keywords}

Appetite $\cdot$ Acetylcholine $\cdot$ Hydration $\cdot$ Osmolality $\cdot$ Thirst . Xerostomia

\begin{abstract}
Introduction: Currently, the conceptualization of thirst is based nearly entirely on osmoregulation, with some acknowledgment of anticipatory-thirst, though with no testable mechanism. Such a model of thirst is unable to explain many thirstrelated phenomena, such as why drinking can occur with hypoosmolality or how quantity of intake at a drinking occasion is regulated. Discussion: This model aimed to unify various lines of thinking from different disciplines surrounding thirst by presenting a 4-compartment model comprising true-thirst (primarily osmo-regulated), contextual-thirst (e.g., mouthbreathing), pharmacological-thirst (induced from drugs), and impulsive-thirst (everyday spontaneous drinking). Within this framework, xerostomia (dry mouth) is the primary regulator of drinking, with a further differentiation between a literal dry mouth ("true-xerostomia," hyposalivation) and the sensation of dry mouth ("sensational-xerostomia," a typically nonoverwhelming desire to drink based on a feeling of dry mouth without hyposalivation). Based on pharmacological-thirst mechanisms, the cholinergic system is proposed to initiate impulsive-thirst by triggering a (sensation of) dry mouth in everyday life. Food-appetite constructs that are centrally regulated (sensory-specific satiety, palatability, and pleasantness) are applied to thirst to explain everyday drinking patterns. Con-
\end{abstract}

clusion: This model helps to explain some anomalies that are thus far unexplained by true-thirst, though there are several other factors which may need to be included after further exploration in the future.

(c) 2022 The Author(s).

Published by S. Karger AG, Basel

\section{Statement of Ethics}

This is a theory paper; no human or animal participants were used as no study was conducted.

\section{Conflict of Interest Statement}

H.A.C. has received research funding from the Economic and Social Research Council, the European Hydration Institute, and the Esther Olssons stiftelse II \& Anna Jonssons Minnesfond; has conducted research for Tate \& Lyle; has received speakers fees from Danone Research; has a scientific advisory role at Hyduro; and holds an honorary research position at the University of Aberdeen.

\section{Funding Sources}

No funding was acquired for this work.

\section{Data Availability Statement}

No data were collected for this theory paper; as such there are no accompanying data. Full paper available from doi: 10.31232/ osf.io/q7gvd.
C 2022 The Author(s).

Published by S. Karger AG, Basel

This article is licensed under the Creative Commons Attribution 4.0 International License (CC BY) (http://www.karger.com/Services/ OpenAccessLicense). Usage, derivative works and distribution are permitted provided that proper credit is given to the author and the original publisher.
Correspondence to:

Harriet A. Carroll, hc12591@ my.bristol.ac.uk 